\title{
Mesulergine in early Parkinson's disease: a double blind controlled trial
}

\author{
E DUPONT, B MIKKELSEN, J JAKOBSEN
}

From the University Department of Neurology, Municipal Hospital, Aarhus, and Department of Neurology, Hjørring Hospital, Denmark

SUMMARY The efficacy and tolerance of treatment with an 8-alpha-amino-ergoline derivative CU32-o85, Mesulergine, were compared with levodopa/benserazide (Madopar) in a 3 month double-blind controlled trial in 31 patients with Parkinson's disease, not previously treated with levodopa. The two treatments were equally well tolerated, and neither dyskinesias nor dose-related fluctuations developed. In $90 \%$ of the patients treated with Mesulergine, Parkinsonian symptoms improved, and at the dose given the overall therapeutical response was two-thirds that of levodopa. During further 9 months of open study the beneficial effect was maintained equally well in both groups. Compared with other dopamine agonists Mesulergine has a considerable antiparkinsonian effect. Unfortunately, further clinical evaluation of the compound recently has been stopped owing to sex and species specific histological alterations in rats. It is suggested that Mesulergine derivatives might well be of value in future treatment of early Parkinson's disease and of late incompensated stages.

The main difficulty in the present treatment of Parkinson's disease is the waning of response to levodopa therapy with occurrence of on-off phenomenons and hyperkinesias. ${ }^{1}$ The reason for this is not understood but likely mechanisms are progression of the disease with further loss of nigrostriatal neurons, degenerative alterations of the dopamine receptors or a deleterious effect of exogenous dopamine or its metabolites on the receptor complex. ${ }^{2-3}$ The latter suggestion has lead to the idea that levodopa therapy has a finite period of optimal usefulness. The practical consequences is that delay of start of levodopa treatment could prolong the period in which therapeutical compensation is possible.

Efforts to substitute levodopa in the initial phase of the disease as well as to compensate for the loss of therapeutical efficacy in the later stages have focused on dopamine agonists. ${ }^{4-5}$ Bromocriptine has been studied widely. In initial studies it was found beneficial in more than half the patients but side effects as nausea, orthostatic hypotension and mental disturbances have been a major problem. ${ }^{6-9}$ Less ad-

Address for reprint requests: E Dupont, MD, University Department of Neurology, Aarhus Kommunehospital, DK-8000, Aarhus, Denmark.

Received 12 April 1985 and in revised form 20 July 1985. Accepted 23 July 1985 verse effects but also somewhat lower beneficiab effects have been observed in recent studies using verye slow increase of doses and low-dose regimen. ${ }^{10} \mathrm{Ap}$ interesting observation is that prospective studies on? the effect of bromocriptine therapy alone in previously untreated patients have so far (five and eight years) not lead to drug-related fluctuations as those occurring with levodopa therapy. ${ }^{1-13}$

During the past few years a series of ergolinederivatives with dopaminomimetic properties have been developed. ${ }^{14}$ One of these, an 8-alphaamino-ergoline, Mesulergine (CU 32-085), influences the striatal dopamine metabolism in the rat in a timedependent biphasic manner: first by enhancing dopamine turnover similar to the effect of dopamine antagonists and subsequently by a reduction of the dopamine metabolism as characteristically described for dopamine agonists. ${ }^{15}$ From in vitro studies there is evidence that Mesulergine itself acts as a dopamine antagonist, whereas its metabolities exert dopaminemimetic effects. ${ }^{16}$

The efficacy of Mesulergine in the treatment of Parkinsonism has been shown in several pilot studies. ${ }^{17-20}$ In one study Mesulergine was compared with placebo ${ }^{21}$ and in another one with bromocriptine. ${ }^{22}$ We report the first controlled doubleblind study of the response to treatment with Mesulergine as compared with levodopa in new pa- 
tients with Parkinson's disease.

\section{Patients and methods}

The study was a double-blind randomised trial on the therapeutic efficacy and tolerance of Mesulergine as compared with standard medication with levodopa in patients with recently diagnosed Parkinson's disease previously untreated with levodopa. Two neurological departments participated in the study. In both centres treatment and evaluation of effect was conducted by one single and experienced neurologist. Patients were recruited to the trial from May 1982 to September 1983.

Eligibility and exclusions Eligible for participation were patients with recently diagnosed and definite idiopathic or postencephalitic Parkinsonism not previously treated with antiparkinsonian medication other than anticholinergics or amantadine. Exclusion criteria were severely impaired general health, any disease influencing absorption, metabolism or excretion of drugs, known allergy to any medication, significant cardio-vascular disease, mental disturbances, dementia and age above eighty years.

Randomisation and treatment schedule Following informed consent patients were randomly assigned by a nonparticipating observer to treatment with either Mesulergine or levodopa. Blindness of physicians and patients were maintained for at least a three months period of study. Subsequently the code was broken for four consecutive patients at a time and the study was continued as an open trial for additional nine months.

The 8-alpha-amino-ergoline derivative CU 32-085, Mesulergine (Sandoz) and levodopa/benserazide (Madopar ${ }^{R}, 4: 1$ fixed ratio combination of levodopa and the decarboxylase inhibitor benserazide, Hoffmann La Roche) were administered in identical capsules in quantities of presumed equipotent antiparkinson effect $(0.5 \mathrm{mg} / 25 \mathrm{mg}, 1.0 \mathrm{mg} / 50 \mathrm{mg}$, $2.5 \mathrm{mg} / 125 \mathrm{mg}$ and $5.0 \mathrm{mg} / 250 \mathrm{mg}$ respectively). Initial doses were $0.5 \mathrm{mg}$ Mesulergine or $25 \mathrm{mg}$ Madopar $^{R}$ once a day. Doses were increased every 3-4 days by increments of $0.5 \mathrm{mg}$ Mesulergine or $25 \mathrm{mg}$ Madopar $^{k}$, the daily dose being distributed over 2-4 intakes. After the 20th day of treatment the daily dose was increased every 3-4 days by increments of $1.0 \mathrm{mg}$ or $50 \mathrm{mg}$, respectively, until a satisfactory therapeutic response was obtained or until significant side-effects appeared. Maximum daily doses of Mesulergine and Madopar $^{R}$ were $30 \mathrm{mg}$ and $1500 \mathrm{mg}$, respectively. Additional anti-parkinsonian treatment with anticholinergics or amantadine was kept unchanged during the study.

Baseline studies Prior to commencement of therapy all patients had a complete clinical and routine neurological examination. A number of routine clinical laboratory examinations were performed including bloodpressure, ECG, haemoglobin, red cell, platelet and total and differential white cell counts, sedimentation rate, urea, creatinine, SGOT, alkaline phosphatase, bilirubine, electrolytes, uric acid, cholesterol and glucose. Urine was examined for protein, glucose, urobilinogen, epithelial cells, erythrocytes and leucocytes. These tests were repeated five times throughout the twelve months period of study at scheduled intervals.

Evaluation and follow-up Patients were evaluated for signs of Parkinsonism by means of the Webster (W) and the Col- umbia University (CU) rating scales ${ }^{23-24}$ at start of therapy and $7,30,60,90,180$ and 360 days later. Scoring was each time made without consideration to previous ratings.

Withdrawals Patients who withdraw from the study because of insufficient efficacy or side-effects were included with available date in the statistical analysis.

Statistics Improvement of symptoms of Parkinsonism is the change in scoring at a given time interval in relation to the start value $\left[\left(\right.\right.$ score $_{\text {start }}-$ score $\left._{\text {end }}\right) /\left(\right.$ score $\left.\left._{\text {start }}\right)\right] \times 100$. Values are arithmetic group means \pm SEs. Within each group of medication results of clinical scoring were compared to pretreatment values by the paired Students $t$ test. Comparison of data between the two groups was made by the unpaired Students $t$ test. The level of significance was $5 \%$.

\section{Results}

A total of 36 patients was eligible for admission to the study. Two patients were excluded because of psychiatric disease and dementia, two because of cardiovascular disease and one refused participation in the trial. The study thus comprised 31 patients. Following randomisation 18 patients were allocated to treatment with Mesulergine and 13 patients to treatment with levodopa/benserazide. Table 1 shows data of age, sex, duration of disease, previous treatment and stage of disability. ${ }^{25}$ The data are comparable and without any significant differences between the two groups.

Among 28 laboratory tests of blood and urine only one changed significantly during treatment. Monocyte counts were reduced by $32 \%$ following 90 days of treatment with Mesulergine, whereas other haemotological parameters remained normal. Tests of cardiovascular functions remained unchanged during study with both medications.

Results of the three months double-blind trial Over-all efficacy and drug tolerance were evaluated in a scale from 0 (poor) to 4 (excellent) at the end of the three months period of treatment or at time of drop-out. Over-all efficacies evaluated by the physicians were $3.1 \pm 0.4$ and $2.2 \pm 0.2$ for the levodopa/benserazide and the Mesulergine treated

Table 1 Number, sex, age and clinical data of Parkinsonism and doses of treatment in the two groups of patients given either the 8-alpha-amino-ergoline Mesulergine or levodopa/benserazide (Madopar ${ }^{R}$ ). Values are mean $\pm S E$ 's and numbers.

\begin{tabular}{lll}
\hline & Mesulergine & Madopar \\
\hline Number of patients (n) & 18 & 13 \\
Sex, females (n)/males (n) & $12 / 6$ & $8 / 5$ \\
Age (yr) & $65 \pm 1 \cdot 9$ & $65 \pm 3 \cdot 8$ \\
Duration of disease (yr) & $2 \cdot 5 \pm 0 \cdot 4$ & $3 \cdot 2 \pm 0 \cdot 5$ \\
Stage of disability 25 & $2 \cdot 7 \pm 0 \cdot 2$ & $2 \cdot 4 \pm 0 \cdot 3$ \\
Patients treated with & 11 & 4 \\
$\quad$ anticholinergics (n) & $25(8-30)$ & $996(200-1500)$ \\
Dose of medication & & \\
\hline
\end{tabular}


Table 2 Side-effects of treatment in 18 patients given the 8-alpha-amino-ergoline derivative, Mesulergine and in 13 patients given levodopa/benserazide (Madopar $\left.{ }^{R}\right)$. Data are numbers and percentages ( )

\begin{tabular}{lll}
\hline & Mesulergine & $\begin{array}{l}\text { Levodopa/ } \\
\text { benserazide }\end{array}$ \\
\hline $\begin{array}{l}\text { Patients who complained } \\
\text { of side-effects }\end{array}$ & $10(56)$ & $8(62)$ \\
$\begin{array}{l}\text { Complaints } \\
\text { Nausea }\end{array}$ & $8(44)$ & $3(23)$ \\
Vomiting & $2(11)$ & $2(15)$ \\
Diarrhoea & 0 & $1(8)$ \\
Sedation & $5(28)$ & $1(8)$ \\
Dizziness & $5(28)$ & $3(23)$ \\
Insomnia & $1(6)$ & 0 \\
Confusion & $1(6)$ & 0 \\
Psychosis (depression) & 0 & $1(8)$ \\
Palpitations & $2(11)$ & 0 \\
Sweating & $1(6)$ & 0 \\
\hline
\end{tabular}

groups, respectively, the difference being statistically significant $(p<0.05)$

The patient's own evaluation of overall efficacy showed a similar tendency to a better response to levodopa $(0.05<\mathrm{p}<0.1)$. The values were $2.8 \pm 0.4$ and $1.9 \pm 0.3$, respectively. Combined overall efficacy scores by patients and psysicians showed effect of treatment in $92 \%$ of those given the ergoline derivative as compared to $88 \%$ in the levodopa treated group. In general treatment was well tolerated. Tolerance as evaluated by the physicians was identical in the two groups.

In table 2 side-effects reported at any interval throughout the study are shown for both medications. Two patients treated with Mesulergine refused to continue participation owing to nausea and general discomfort, one of them after two single doses only, the other after four weeks of treatment. In the levodopa group treatment was discontinued by one patient because of lack of efficiency. This patient as the one of the whole group had a postencephalitic Parkinsonian syndrome with unilateral tremor and rigidity untreated for forty years.

Figure 1 shows the effect of the treatment with levodopa/benserazide and Mesulergine on total score, bradykinesia, rigidity and tremor evaluated on the $\mathrm{W}$ and the CU rating scales at start of treatment and 7 , 30,60 and 90 days later. It appears that treatment with both drugs improved all scores of disability significantly as compared to pretreatment values.

In table 3 the improvement of treatment with levodopa/benserazide and Mesulergine to the clinical signs of Parkinsonism is compared. On the basis of total scores levodopa was superior to treatment with Mesulergine $(0.05<\mathrm{p}<0.06)$. Levodopa had a significantly better effect on bradykinesia and tremor than the test drug, whereas the effect to rigidity of both drugs was very similar.
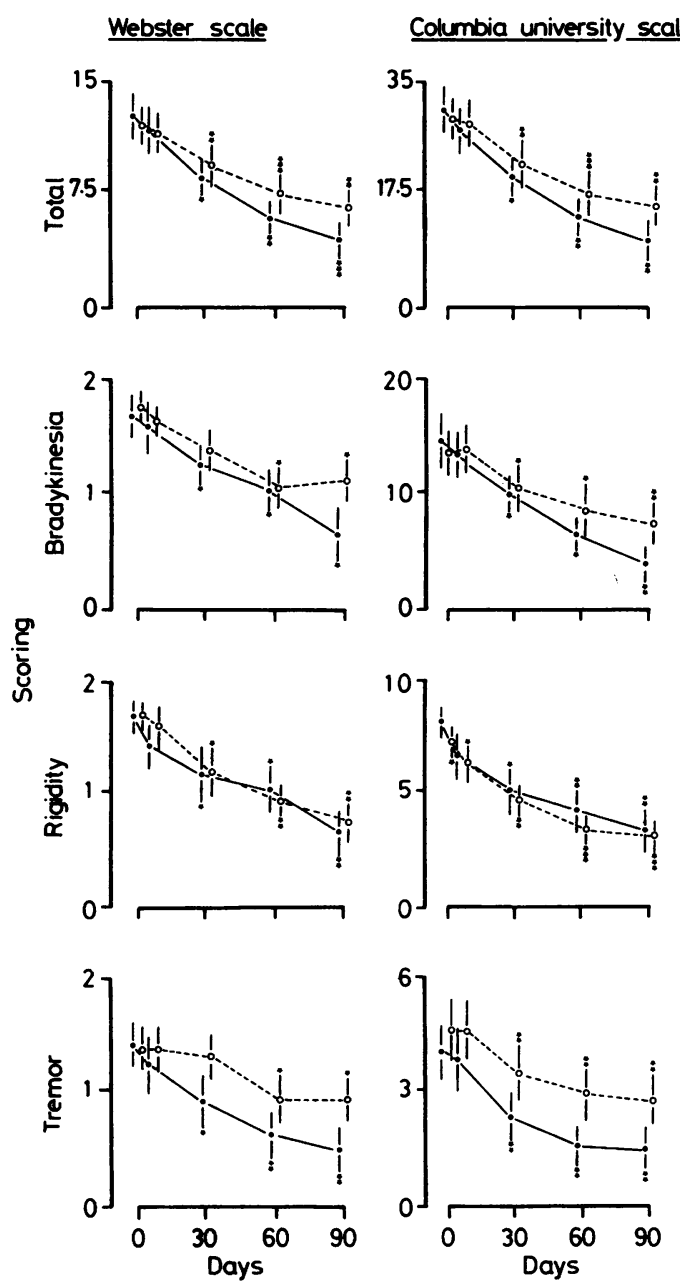

Fig 1 Total scores of neurological signs of Parkinson's disease and of bradykinesia, rigidity and tremor according to the Webster and the Columbia University scales at start and following 7, 30,60 and 90 days of treatment in a double-blind study with either the ergoline derivative Mesulergine (O) or levodopa/benserazide (O). Values are group means + ISEs. Asterisks indicate statistical significant difference from start value, ${ }^{*}<0.05, * *<0.001, * * *<0.00001$.

Results of the one-year trial Following the end of the double-blind trial the study was continued in an open $ᄋ$ fashion for further nine months. Two patients in the $>$ test group and two in the levodopa treated group withdrew from the trial for reasons unrelated to $N$ effects of the medications. Among patients treated for one year none developed dyskinesias or dose-related $N$ fluctuations. Figure 2 show the mean of total score $\underset{\omega}{N}$ and of bradykinesia rigidity and tremor according to 
Table 3 Improvement of clinical signs of Parkinsonism following 3 months of treatment with either levodopa/benserazide (Madopar ${ }^{\mathrm{R}}$ ) or the 8-alpha-amino-ergoline derivative Mesulergine. Group mean values are given as a percentage of pretreatment score $\left[\left(\right.\right.$ score $_{\text {start }}-$ score $\left._{\text {end }}\right) /\left(\right.$ score $\left.\left.\left._{\text {start }}\right)\right]\right) \times 100$

Webster scale Columbia University scale

\begin{tabular}{|c|c|c|c|}
\hline Total score & Levodopa/benserazide & $65 \pm 8 \%$ & $68 \pm 7 \%$ \\
\hline 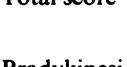 & $\begin{array}{l}\text { Mesulergine } \\
\text { Levodopa/benserazide }\end{array}$ & $\begin{array}{l}47 \pm 5 \% \\
63 \pm 13 \%\end{array}$ & $\begin{array}{l}47 \pm 7 \% \\
76 \pm 7 \%\end{array}$ \\
\hline Bradykinesi & $\begin{array}{l}\text { Mesulergine } \\
\text { Levodopa/benserazide }\end{array}$ & $\begin{array}{l}0.05<p<0.01 \\
30 \pm 13 \% \\
71 \pm 10 \%\end{array}$ & $\begin{array}{l}p<<0 \cdot( \\
41 \pm 12 \% \\
62 \pm 11 \%\end{array}$ \\
\hline Rigidity & $\begin{array}{l}\text { Mesulergine } \\
\text { Levodopa/benserazide }\end{array}$ & $\begin{array}{l}57 \pm 10 \% \\
63 \pm 13 \%\end{array}$ & $\begin{array}{l}67 \pm 7 \% \\
62 \pm 9 \%\end{array}$ \\
\hline Tremor & Mesulergine & $28 \pm 9 \%{ }^{p<0.05}$ & $40 \pm 8 \% \quad 0.05<p<0.1$ \\
\hline
\end{tabular}

\section{Webster scale}
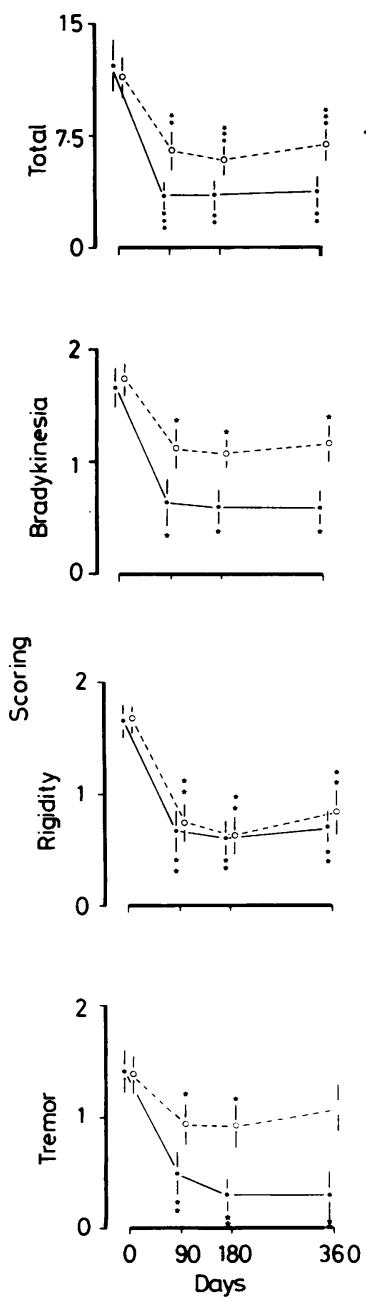

\section{Columbia University scale}
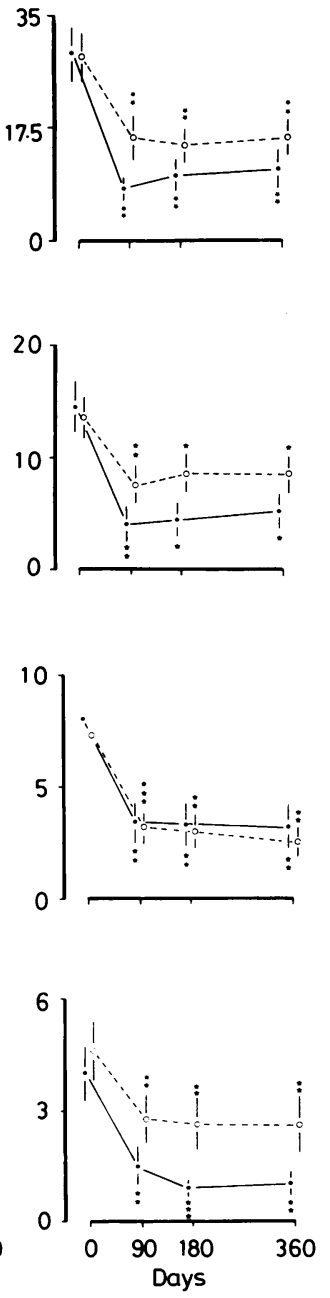

the $\mathrm{W}$ and the $\mathrm{CU}$ rating scales at the start and after 90,180 and 360 days of treatment. After one year the antiparkinsonian effect obtained during the initial 90 days of study was maintained at an almost identical level in both groups. The combined total scores of both rating scales resulted in a $42 \%$ improvement in patients treated with Mesulergine as compared to $67 \%$ in the levodopa group. Again the effect on rigidity was similar in the two groups whereas the antiparkinsonian effects on bradykinesia and tremor were significantly greater in levodopa treated patients.

\section{Discussion}

This double-blind trial of treatment with Mesulergine (CU 32-085) compared with traditional treatment with levodopa combined with decarboxylase inhibitor (Madopar ${ }^{R}$ ) has shown that Mesulergine has a stronger although less potent therapeutic effect than levodopa in "de novo" patients not previously treated with any of these medications. Ninety percent of the patients in the Mesulergine group improved during treatment and the efficacy was as high as two-thirds that of levodopa. In treatment of bradykinesia and tremor levodopa was superior to Mesulergine whereas the effect on rigidity of the two drugs was similar. Also, it is noteworthy that the beneficial therapeutic response did not fail during the one year period of open study.

Fig 2 Total scores of neurological signs of Parkinson's disease and of bradykinesia, rigidity and tremor according to the Webster and the Columbia University scales at start and following 90, 180 and 360 days of treatment with either the ergoline derivative Mesulergine ( $\bigcirc$ ) or levodopa/benserazide (O). During the first 3 months the study was conducted as a double-blind trial and subsequently was continued in an open fashion. Values are group means $+1-S E$ 's. Asterisks indicate statistical significant difference from start value, $*<0.05,{ }^{* *}<0.001$ and ${ }^{* * *}<0.00001$. 
There are few reports in the literature on the antiparkinson effect of Mesulergine. The present study is the first double-blind controlled trial. Most studies have been performed in advanced cases of Parkinson's disease and report potent anti-parkinsonian effects of the drug combined with a reduction in dosage of levodopa therapy. ${ }^{17-20-22}$ Schneider et $\mathrm{ll}^{20}$ studied the effect of Mesulergine in a larger group of patients with mixed duration of disease. In comparison to bromocriptine, the most commonly used dopamine agonist, it seems that Mesulergine has a stronger antiparkinsonian effect. ${ }^{20-22}$ In four recently diagnosed and untreated patients a favourable response was obtained for a one year period of open study. The most striking effect was on rigidity and tremor whereas akinesia improved less. ${ }^{20}$ Teräväinen et al treated 12 "de novo" patients with Mesulergine for five months with slowly increasing doses until a maximum of $7 \mathrm{mg}$ per day and obtained a moderate but significant improvement of all symptoms compared to the pretreatment state as well as to a later placebo period. ${ }^{21}$

In the present study using maximal doses of $30 \mathrm{mg}$ per day of Mesulergine (mean $25 \mathrm{mg}$ ) and $1500 \mathrm{mg}$ per day of Madopar ${ }^{R}$ (mean $996 \mathrm{mg}$ ) the two medications were equally well tolerated. In order to examine the doses of "equipotent" Mesulergine, necessary to eliminate the Parkinsonian symptoms, the doses of levodopa in the present trial have been higher than normally recommended in "de novo" patients and higher than necessary to obtain relief of symptoms. It is possible, however, that still higher dosages of Mesulergine will lead to a greater antiparkinsonian effect than was obtained in the present study.

Corresponding to preclinical findings where Mesulergine was several times less potent than bromocriptine in producing side effects, ${ }^{16}$ it seems that the compound is better tolerated in Parkinsonian patients than bromocriptine. ${ }^{22}$ Our own experiences in uncontrolled treatment of patients with advanced Parkinson's disease by combinations of levodopa plus bromocriptine or Mesulergine suggest a better tolerance of combination therapy with Mesulergine.

Recently, Sandoz Ltd decided to stop further clinical development of CU 32-085 because of toxicological observations in animal experiments. Preliminary evaluation of a long-term rat carcinogenicity study revealed interstitial cell tumours in the testes which only became apparent in the last third of lifelong (that is $21 / 2$ years) treatment. Female rats remained healthy and in the mouse carcinogenicity study no testicular tumours were encountered. The findings suggest a sex-related phenomenon specific for the rat and there is no evidence that similar changes have occurred in Mesulergine treated patients (personal communication). ${ }^{26}$ Mesulergine de- rivatives without teratogenic side-effects might well have a similar high efficiency and tolerance as the one we studied. Future controlled studies should clarify whether such treatment will delay the appearance of an incompensated Parkinsonian state.

Sandoz A/S, Copenhagen and cand.pharm. Niels Børresen are thanked for their help and support.

\section{References}

${ }^{1}$ Marsden CD, Parkes JD. "On-off" effects in patients with Parkinson's disease on chronic levodopa therapy. Lancet 1976;i:292-6.

${ }^{2}$ Lesser RP, Fahn S, Snider SR, Cote LJ, Isgreen WP, Barrett RE. Analysis of the clinical problems in parkinsonism and the complications of long-term levodopa therapy. Neurology (Minneap) 1979;29:1253-60.

${ }^{3}$ Graham DG, Tiffany SM, Bell WR, Gutknecht WF. Auto-oxydation versus covalent binding of quinones as the mechanism of toxicity of dopamine, 6-hydroxy-dopamine and related compounds toward C 1300 neuroblastoma cells in vitro. Mol Pharmacol 1978;14:644-53.

${ }^{4}$ Lieberman AN, Goldstein M. Treatment of advanced Parkinson's disease with dopamine agonists. In: Marsden CD, Fahn S, eds. Movement Disorders, Butterworths International Medical Reviews 1982:146-73.

${ }^{5}$ Quinn NP. Anti-Parkinsonian Drugs Today. Drugi 1984;28:236-62.

${ }^{6}$ Parkes JD, Debono AG, Marsden CD. Bromocriptine parkinsonism. Longterm treatment, dose response and comparison with levodopa. J Neurol Neurosus Psychiatry 1976;39:1101-8.

${ }^{7}$ Calne DB, Plotkin C, Williams AC, Nutt JG, Neophytides A, Teychenné PF. Long-term treatment of parkinsonism with bromocriptine. Lancet 1978;i:735-8.

${ }^{8}$ Fahn S, Cote LJ, Snider SR, Barrett RE, Isgreen WF. The role of bromocriptine in the treatment of parkinsonism. Neurology (Minneap) 1979;29:1077-83.

${ }^{9}$ Lieberman AN, Kupersmith MD, Gopinathan G, Estey E, $\overrightarrow{\vec{\partial}}$ Goodgold A, Goldstein M. Bromocriptine in Parkinson 3 disease. Further studies. Neurology (Minneap) 1979;29:363-9.

${ }^{10}$ Teychenné PF, Bergsrud D, Raey A, Elton RL, Vern B. Bromocriptine low dose therapy in Parkinson disease. Neurology (NY) 1982;32:577-83.

${ }^{11}$ Lees AJ, Stern GM. Sustained bromocriptine therapy in previously untreated patients with Parkinson's disease. J Neurol Neurosurg Psychiatry 1981;44:1020-3.

${ }^{12}$ Rascol A, Montastrug JL, Ciuraud-Chaumeil B, Clanet M. Bromocriptine as the first line treatment of Parkin- 0 son's disease. Long-term results. Rev Neurol (Paris) 1982;138(5):401-8.

${ }^{13}$ Grimes JD, Delgado MR, Gray P. Low-dose bromocriptine therapy in "de novo" Parkinson's disease. N Indication, dosage, initial response rate and adverse effects. Neurology $(N Y)$ 1983;33(suppl 2): 112.

${ }^{14}$ Flückiger E, Briner U, Bürki HR, Marbach P, Wagner N HR, Doepfner W. Two novel prolactin release- 
inhibiting 8-alpha-amino-ergolines. Experientia 1979;35:1677-8.

${ }^{15}$ Enz A. Biphasic influence of an 8-alpha-amino-ergoline, CU32-085, on striatal dopamine synthesis and turnover in vivo in the rat. Life Sci 1981;29:2227-8.

${ }^{16}$ Enz A, Donatsch P, Flückiger E, Jaton A, Markstein R, Palacios JM. Pharmacological profile of Mesulergine. In: del Pozo E, Flückiger E, eds. Dopamine and Neuroendocrine Active Substances. London: Academic Press, 1985 (in press).

${ }^{17}$ Biesmeyer H, Ludin HP, Ringwald E. Therapeutic experience with the new dopamine agonist CU32-085 in advanced Parkinson's disease. J Neurol 1983;230:19-23.

${ }^{18}$ Pakkenberg H, Jensen I. Treatment of Parkinson's disease with the Ergoline Derivatives CQ32-084 and CU32-085. In: Fahn S, Calne DB, Shoulson I, eds. $A d-$ vances in Neurology, vol 37, Experimental Therapeutics of Movement disorders. New York: Raven Press 1983:151-7.

${ }^{19}$ Ringwald E, Hirt D, Markstein R, Vigouret JM. Dopaminrezeptoren-Stimulatoren in der Behandlung der Parkinsonkrankheit, Nervenarzt 1982;53:67-71.

${ }^{20}$ Schneider E, Hubener K, Fischer P-A. Treatment of Par- kinson disease with 8-alpha-amino-ergoline, CU32-085. Neurology (NY) 1983;33:468-72.

${ }^{21}$ Teräväinen $\mathrm{H}$, Huttunen J, Heitanen M. Mesulergine in the treatment of Parkinson's disease. In: del Pozo E, Flückiger E, eds. Dopamine and Neuroendocrine Active Substances. London: Academic Press, 1985 (in press).

${ }^{22}$ Schneider E, Baas H, Fischer P-A. Long-term comparison between bromocriptine and 8-alpha-amino-ergoline, CU32-085, in advanced parkinsonism. In: del Pozo E, Flückiger E, eds. Dopamine and Neuroendocrine Active Substances. London: Academic Press, 1985 (in press).

${ }^{23}$ Webster DD. Critical analyses of the disability in Parkinson's disease. Medical Treatment (New York) 1968;5:257-82.

${ }^{24}$ Duvoisin RC. The evaluation of Extrapyramidal Disease. In: de Ajuriaggera J, ed. Monoamine, Noyaux Gris Centraux et Syndrome de Parkinson. Paris: Masson 1970:313-25.

${ }^{25}$ Hoehn MM, Yahr MD. Parkinsonism: onset, progression and mortality. Neurology (Minneap) 1967;17:427-42.

${ }^{26}$ Letter to all CU 32-085 investigators from Sandoz Ltd, Pharmaceutical Division, Basle, Switzerland. $30 \mathrm{Au}$ gust, 1984; ref 3109/PK/UA. 